\title{
Erratum
}

\section{Plasma lactate concentration increases as a parabola with delay during ramp exercise}

\author{
François Péronnet ${ }^{1}$, R. Hugh Morton ${ }^{2}$ \\ ${ }^{1}$ Département d'éducation physique, Université de Montréal, CP 6128-A, Montreal, Canada, H3C 3J7 \\ ${ }^{2}$ Department of Statistics, School of Mathematical and Information Sciences, Massey University, PB 11222, Palmerston North, \\ New Zealand
}

Eur J Appl Physiol (1994) 68:228-233

We unfortunately overlooked two mistakes in Table 1 . The values given for a/ $S$ were actually those of a, with $S$ (the extramuscular lactate space) assumed to be 181 . The correct values of a in $\mathrm{mmol} \cdot \mathrm{l}^{-1} \cdot \mathrm{min}^{-2}$ are indicated below. In addition, the fourth column of the table in fact showed the value for the delay $\delta$, in minutes. We apologize for these mistakes, which escaped our attention.

Table 1. Results of the analysis of the lactate curve

\begin{tabular}{llllll}
\hline Subjects & $\begin{array}{l}{\left[\mathrm{La}^{-}\right]_{0}} \\
\left(\mathrm{mmol} \cdot \mathrm{l}^{-1}\right)\end{array}$ & $\begin{array}{l}\mathrm{a} / S \\
\left(\mathrm{mmol} \cdot \mathrm{l}^{-1} \cdot \mathrm{min}^{-2}\right)\end{array}$ & $\begin{array}{l}\delta \\
(\mathrm{min})\end{array}$ & $\begin{array}{l}\mathrm{MRS}^{0.5} \\
\left(\mathrm{mmol} \cdot 1^{-1}\right)\end{array}$ \\
\hline 1 & 0.87 & 0.191 & 7.17 & 0.996 & 0.123 \\
2 & 0.99 & 0.115 & 4.67 & 0.999 & 0.082 \\
3 & 1.27 & 0.130 & 5.87 & 0.994 & 0.062 \\
4 & 1.04 & 0.220 & 7.70 & 0.998 & 0.109 \\
5 & 0.73 & 0.147 & 5.74 & 0.995 & 0.103 \\
\hline Mean & 0.98 & 0.161 & 6.23 & - & 0.096 \\
SD & 0.20 & 0.044 & 1.21 & - & 0.024
\end{tabular}

$\left[\mathrm{La}^{-}\right]_{0}$, Lactate concentration at rest; a/S, rate of increase in lactate concentration per litre of extramuscular space; $\delta$, delay between the onset of exercise and the linear increase in $\mathbf{R}_{c} ; r$, correlation coefficient; MRS, mean residual square around the fitting curve 